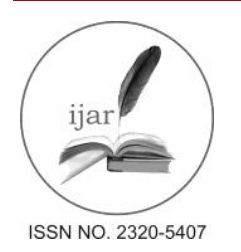

Journal homepage:http://www.journalijar.com
Journal DOI:10.21474/IJAR01

RESEARCH ARTICLE

\title{
A STUDY ON CONSUMERS' PERCEPTION TOWARDS PACKAGED MILK PRODUCTS IN PANIPAT,
} HARYANA.

Manish Phuyal (MBA).

\begin{abstract}
Manuscript Info Abstract
Manuscript History:

Received: 11 April 2016

Final Accepted: 13 May 2016

Published Online: June 2016

Key words:

Packaged milk products, consumer perception

*Corresponding Author

Manish Phuyal.

The production and consumption of fluid milk has been growing in India with time. Despite the availability of packaged milk products in marketplace, large number of people, including urban population, still prefer to go for loose milk.This paper is a result of research conducted to find out how packaged milk is positioned in consumers' mindset and what can be done to encourage its consumption. The research was conducted in Panipat city of Haryana, India with 50 respondents selected using convenience sampling. Primary data was collected using questionnaire schedule and secondary data was collected from articles in journals and published reports. Analysis of data collected from the survey, using SPSS software, revealed that most of the consumers of packaged milk products are not satisfied with the products available in marketplace and majority of them consider the quality of the packaged milk product as the most important criterion for making purchase decisions. Further, it was found that marital status, age and education influence how a consumer perceives packaged milk product, and health impact, offerings and availability are positively correlated with the perception of packaged milk product.
\end{abstract}

Copy Right, IJAR, 2016, All rights reserved:

\section{Introduction:-}

Milk products occupy an important place in people's diet in society like India where vegetarian diet is popular. Milk production and consumption plays a pivotal role in the functioning of Indian economy. With the largest number of cattle population in the world, India ranks second to USA in annual dairy production. Rural economy of India is significantly benefitted by the Milk amongst all the commodities; so much that the total value of milk produced even exceeds the combined value of wheat and rice production. Calendar Year 2015 fluid milk consumption is forecast to increase 4.8 percent to $59.75 \mathrm{MMT}$ on population growth and rising incomes, which has resulted in Indian buying more nutritious food, especially milk and dairy products(Mani \& Intodia, 2014).

Despite the remarkable progress of Indian dairy sector, large proportion of milk is marketed informally and in unorganized sector. The existence of informal market can be due to the lack of willingness of consumers to pay extra cost of packaging and processing the milk. Failure of formal market to keep the costs low due to cost incurring activities like quality control, processing, packaging and taxation are also said to be one of the reasons why it hasn't caught up with informal market. Also, possibly due to the consumer perception that loose milk is fresher and superior in quality than the packaged milk, the sales of packaged milk is comparatively lower than the loose milk. There may be several other factors causing the inferiority of packaged milk in Indian market. Therefore, it is important to study how consumers perceive the packaged milk productand what factors influence its purchase in order to have a clear understanding of how it appeals to consumers and what can be done to make it more appealing.

\section{Problem Statement:-}

Most of the consumers of packaged milk in India comprise of population in urban areas. Most of them are literate and it is assumed that they have knowledge about what ingredients are added, how the milk is processed and packaged along with the possible hazards of packaged milk consumption. But still it is commonly perceived that 
majority of them purchase packaged milk because of non-availability of loose milk and because package milk is convenient for purchase. This study attempts to find out the actual perception of consumer towards packaged milk and factors affecting the purchase of packaged milk.

\section{Objectives:-}

* To study how consumers perceive packaged milk products.

* To study how demographic factors influence the consumer's perception towards packaged milk products.

* To study the factors that influence buying decision regarding packaged milk.

\section{Limitations:-}

* The study is limited to the city of Panipat in Haryana district, India and the findings of this research cannot be extended to other areas or generalized.

* Convenience sampling is used, which has its own limitations.

\section{Literature Review:-}

(Kariyawasam, Jayasinghe-Mudalige, \& Weerahewa, 2006)studied consumer attitude and perception towards a milk product in Sri Lanka. The results indicated that consumers tended to purchase tetra-pack considering the attributes included in value and package subsets mainly, including purity, appearance, size, convenience, and informational labeling etc. However, consumers did not believe that it enhanced those attributes included in "food safety" and "nutritional" subsets. The statistical outcome showed that age, gender, level of education and income had a significant impact on this behavior.

(Kilic, Akbay, \& Tiryaki, 2009)analyzed unpacked and packed milk preferences in Samsun province of Turkey. The results indicated that better educated household head, higher income households, younger and female household head and people who agreed with "unpacked milk is not healthy" consumed more packed fluid milk than did others. Moreover, consumers who agreed with statement "price of packed milk is expensive compare to unpacked milk" were less likely to consume packed fluid milk than did others.

(Aayaz, Badar, \& Ghafoor, 2011)conducted a study amongst 120 consumers of packed milk in 3 cities of Pakistan. The results of the study indicated that consumers mostlyperceive packed milk relatively better due to its various quality attributes. The estimated ordered logistic regression model revealed that younger,married and male consumers irrespective of education level had greaterpreferences for packed milk.

(Yayar, 2012)investigated packed and unpacked fluid milk consumption and preference amongst Turkish households using consumer survey. Empirical results indicated that better educatedhousehold heads, higher income and larger households, and householdswith children under seven years of age consumed more packed milk thanothers. A similar result was found for unpacked milk consumption, exceptfor a negative effect of education, working wife and income.

(Sivasankaran \& Sivanesan, 2013), in their study, found that quality, packaging, price, availability and advertisement were the factors that affected the preference of branded milk in rural and urban areas and affected the consumption pattern.

(Ahmed, Pramar, \& Amin, 2014)conducted a research to assess the impact of packaging on product purchase. According to thefinding of the research study, it was observed that the packaging was the most important factor. It was further concluded that the packaging elements like its Color, Packaging material,Design of Wrapper and innovation were more important factors when consumers making anybuying decision. Finally it has also been concluded that the Packaging is one of the mostimportant and powerful factor, which influences consumer's purchase decision.

(Mousavi \& Jahromi, 2014)conducted a research in Shiraz city with 193 samples using questionnaire. The results of the study indicated that packaging elements such as color, context image, packaging material, style of writing, cover design, printed information and innovation had positive and significant relationship with consumer buying behavior. 
(Sumathi, 2015)in his study of consumers perception towards different brands of packaged milk concluded that, "despite the technological advancement resulting in several variety of packaged milks in market, there is a strong felt need for the marketing managers to focus on creating high degree awareness among consumers regarding their product range".

(Elangovan \& Gomatheeswaran, 2015)found in their study in Tamil Nadu that people preferred retail outlets for purchasing branded milk and milk products and most of the respondents were influenced by the family members for purchase of particular brand of milk.

\section{Research Methodology:-}

Research approach and research design:-

Quantitative approach of research was followed to conduct this study. It included quantifying the information and opinions of respondents into measurable form. Descriptive research design was used to create blueprint for the research process as the finding of the study is supposed to be conclusive.

\section{Population universe and sampling:-}

Population universe for the research consisted of all the residents of Panipat district in Haryana, India. Convenience sampling was used to select a sample of 50 respondentsbased on their willingness to participate in the survey.

\section{Data collection method, tool and scaling:-}

Survey method was used for the collection of data. Questionnaire schedule was used for collecting the data from respondents. The questionnaire consists of 3 sections namely, (1) demographics, (2) Factors influencing buying decision and (3) Satisfaction level with various aspects of packaged milk.Categorical scale is used to record demographic information and itemized rating scale (Likert-type scale) is used to record satisfaction level of respondents with various aspects of packaged milk. The rating scale ranges from 1 to 5,1 being highly dissatisfied and 5 being highly satisfied. Secondary data was collected with the help of articles in journals including online and offline journals and reports from government agencies.

\section{Analysis tools and techniques:-}

Analysis tools used were IBM SPSS and Microsoft Excel. Simple frequency analysis, percentage analysis, T-test, ANOVA and correlation test were the tests performed for the purpose of analyzing the data collected. 
Analysis and Interpretation:-

Demographics:-

Table 1:- Demographic Information.

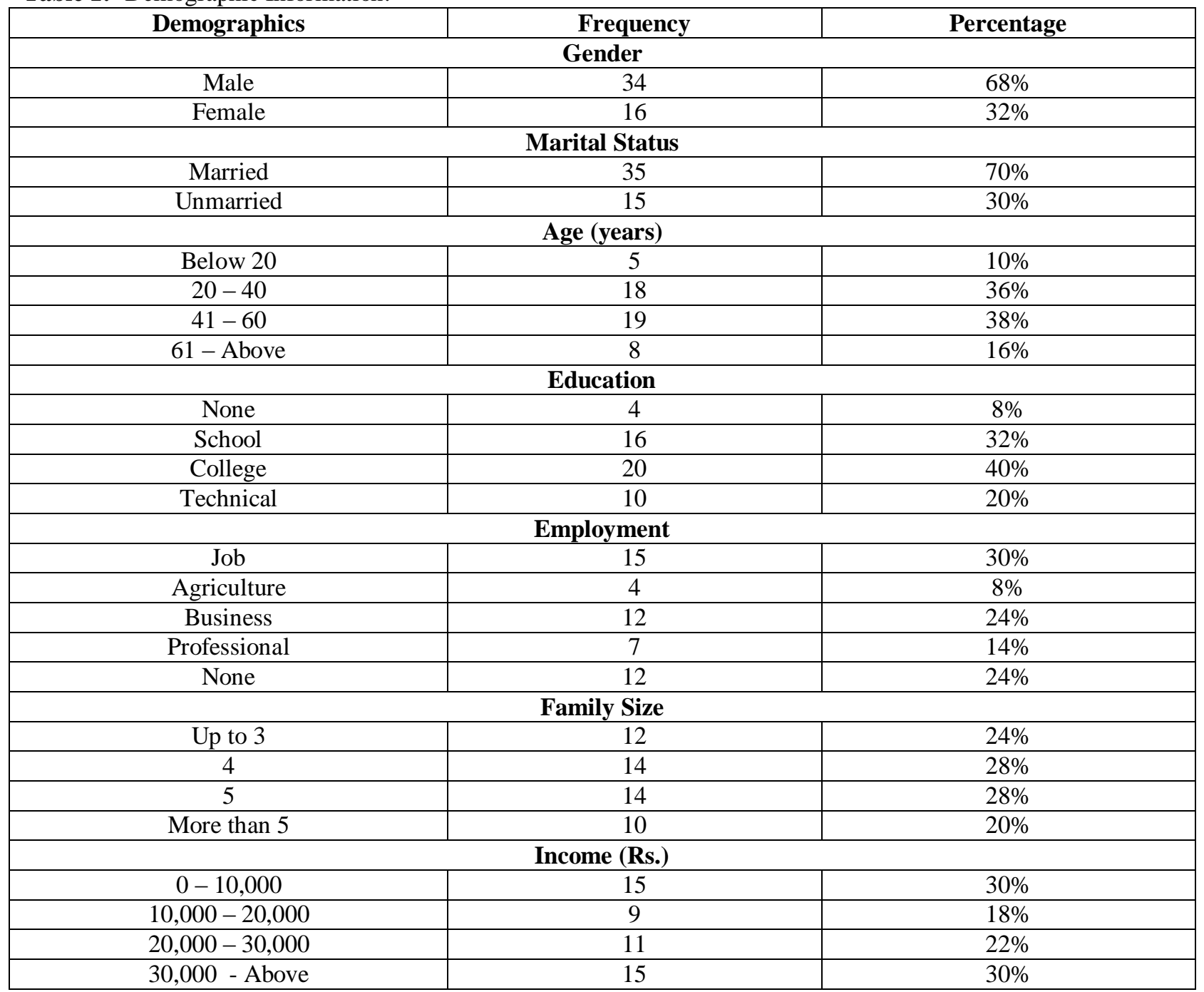

Table 1 shows that majority of respondents of the survey are male (68\%) with $32 \%$ females. $70 \%$ of respondents are married with only $30 \%$ unmarried. The age groups $20-40(36 \%)$ and $41-60(38 \%)$ are in majority. Most of the respondents have completed their school level education (32\%) and college level education (40\%). 30\% respondents work on a job, $8 \%$ agriculture, $24 \%$ business, $14 \%$ are professionals and remaining $24 \%$ do not have employment. $24 \%$ respondents have family size of 3 members, $28 \%$ have 4 members, $28 \%$ have 5 members and rest $20 \%$ have more than 5 members in their family. $60 \%$ of respondents fall in either $0-10,000(30 \%)$ income group or above $30,000(30 \%)$ income group whereas $18 \%$ and $22 \%$ respondents have income of $10,000-20,000$ and $20,000-$ 30,000 respectively.

Comparison of Perceptions: Satisfied vs Unsatisfied:-

To analyze the satisfaction level, average of perception towards various aspects of packaged milk is calculated for each of the respondents which is called overall perception. Overall perception less than or equal to 3 is considered unsatisfied and more than 3 is considered satisfied. 
Figure 1:-Satisfied vs Unsatisfied

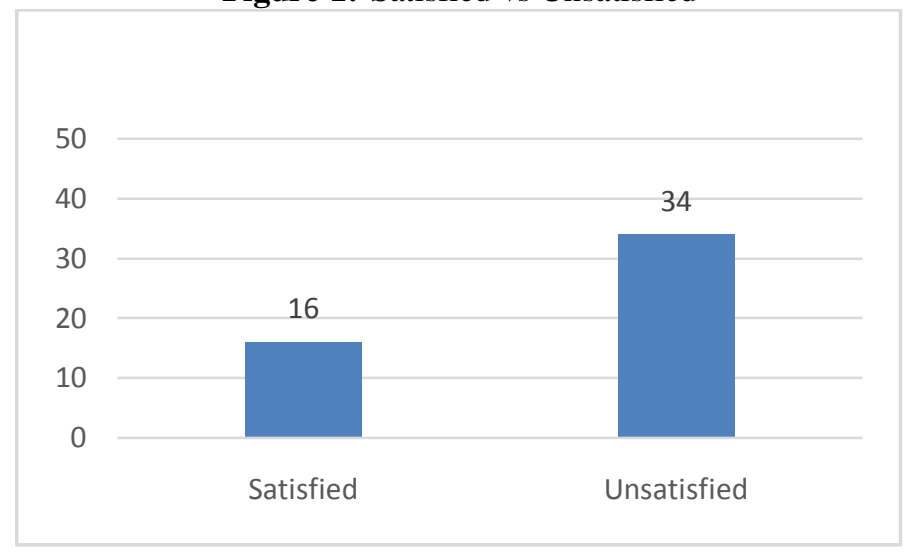

Figure 1 shows that majority of respondents are not satisfied with the packaged milk products they are consuming. 34 respondents $(68 \%)$ are not satisfied with the packaged milk whereas only $16(32 \%)$ are satisfied.

\section{Analysis of Factors influencing buying decision:-}

Figure 2:- Factors influencing buying decision.

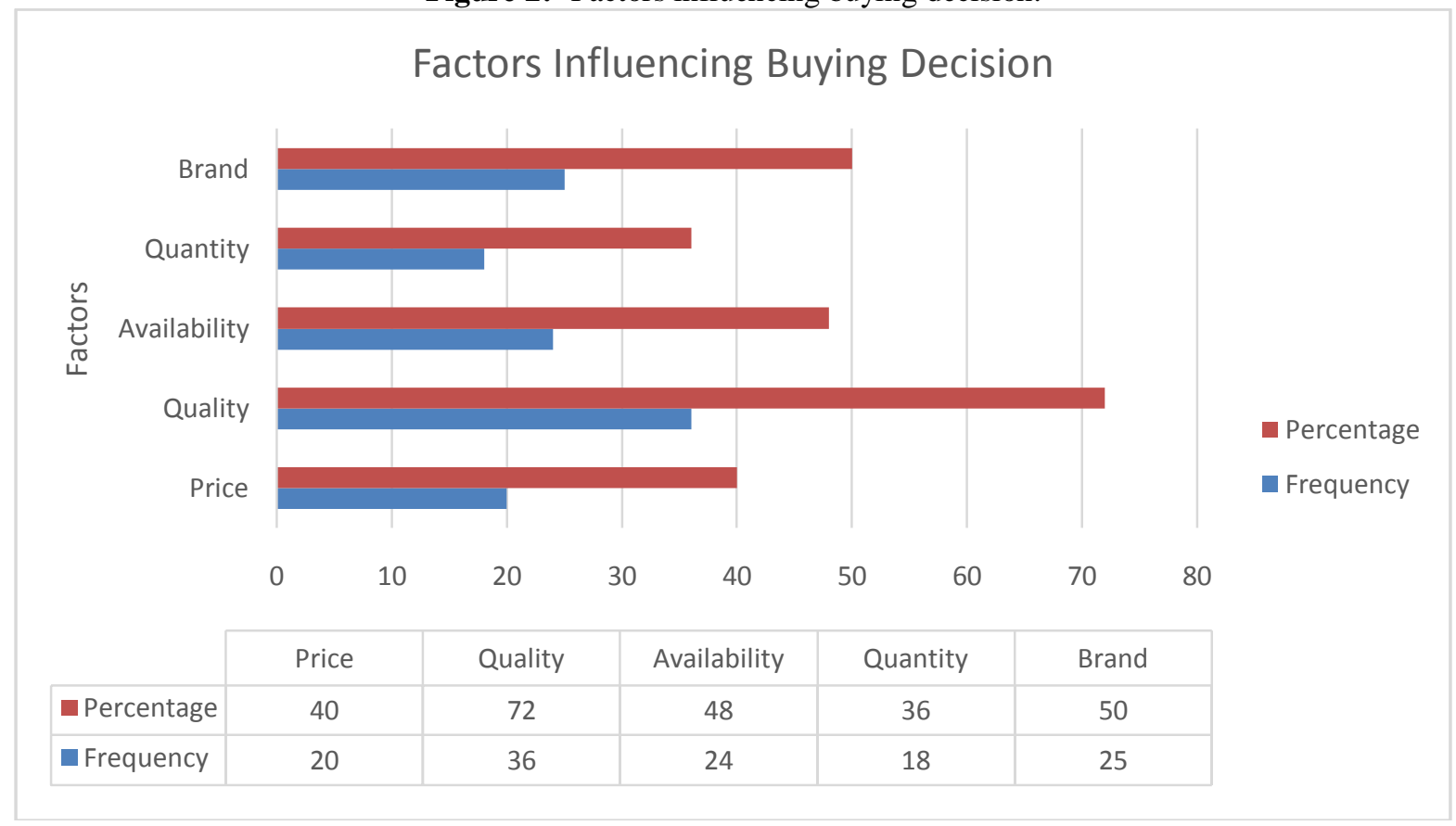

Based on figure 2, it can be said that, large number of people (72\%) consider quality of the packaged milk before purchasing it. Brand (50\%), Availability (48\%) and Price (40\%) are also important for many people for making purchase decision regarding packaged milk product.

Impact of Gender and Marital Status on Perception:-

Table 2:- T-test Results.

\begin{tabular}{|c|c|c|c|}
\hline & T-Value & Degree of Freedom & P-Value \\
\hline Gender vs Perception & -0.34 & 48 & 0.973 \\
\hline Marital Status vs Perception & -2.179 & 48 & $0.034^{*}$ \\
\hline
\end{tabular}

*Significant at 5\% significance level 
T-test revealed that at 5\% (Alpha: 0.05) significance level, with the p-value of 0.973, Gender has no significant association with perception towards packaged milk; whereas, marital status is significantly associated with the perception towards packaged milk.

Impact of Age, Education, Employment, Family size and Income on Perception Table 3:-ANOVA Results.

\begin{tabular}{|c|c|c|}
\hline Factors & F-Value & P-Value \\
\hline Age & 4.783 & $0.006^{*}$ \\
\hline Education & 4.512 & $0.007^{*}$ \\
\hline Employment & 1.203 & 0.323 \\
\hline Family Size & 1.494 & 0.229 \\
\hline Income & 0.397 & 0.756 \\
\hline
\end{tabular}

*Significant at $5 \%$ significance level

Based on the results of ANOVA tests performed on independent variables age, education, employment, family size and income against dependent variable overall perception towards packaged milk, following statements regarding associations can be made:

* Age is significantly associated with perception towards packaged milk

* Education is significantly associated with perception towards packaged milk

* Employment is not significantly associated with perception towards packaged milk

* Family size is not significantly associated with perception towards packaged milk

* Income is not significantly associated with the perception towards packaged milk.

Correlation Analysis:-

Table 4: Correlation between perception on aspects of packaged milk and overall perception

\begin{tabular}{|c|c|}
\hline & Overall Perception \\
\hline Quality & $.564^{* *}$ \\
\hline Quantity & $.620^{* *}$ \\
\hline Health & $.771^{* *}$ \\
\hline Packaging & $.402^{* *}$ \\
\hline Price & $.537^{* *}$ \\
\hline Availability & $.680^{* *}$ \\
\hline Offers and Discounts & $.696^{* *}$ \\
\hline Home Delivery & $.432^{* *}$ \\
\hline Taste & $.543^{* *}$ \\
\hline
\end{tabular}

According to table 4, perception about all the aspects of packaged milk are significantly correlated with overall perception at 5\% significance level. Health, Offer, Availability and Quantity are highly correlated with overall perception and packaging is least correlated.

\section{Summary of Findings:-}

The analysis revealed that large portion of population is still not satisfied with the packaged milk products available in market. Large number of people look for quality before going for packaged milk purchase. Marital status, age and education has significant impact on how people perceive the packaged milk products. Perception about health impact, offers and availability are determining factors on how packaged milk product is perceived.

\section{Conclusion:-}

Based on the findings of the study, there is still a large portion of consumers of packaged milk which is not satisfied with currently available packaged milk products in marketplace. Packaged milk producers can target that segment and use it as an opportunity to expand their sales by satisfying those consumers. For that they will have to make quality their utmost importance in the product as consumers seem to value quality more than any other factors before purchase of packaged milk. Introducing more nutrition to positively influence health, availing offers and discounts, and making milk easily available can hugely improve the perception towards the packaged milk product and help in better positioning of the product in the mindset of consumers. 


\section{References:-}

1. Aayaz, S., Badar, H., \& Ghafoor, A. (2011). Level and Determinants of Consumers' Perception of Packed Milk in Pakistan. Journal of Business and Economics, 60-76.

2. Ahmed, R. R., Pramar, V., \& Amin, A. M. (2014). Impact of Product Packaging on Consumer's Buying Behavior. European Journal of Scientific Research 120 (2), 145-157.

3. Elangovan, N., \& Gomatheeswaran, M. (2015). A study on consumer behaviour towards various brands of milk and milk products with special reference to Thudiyalur town at Coimbatore district in Tamil Nadu. International Journal of Multidisciplinary Research and Development, 595 - 601.

4. Kariyawasam, S., Jayasinghe-Mudalige, U., \& Weerahewa, J. (2006). Assessing Consumer Perceptions Towards Attributes of Food Quality: The Case of Consumption of Tetra-Packed Fresh Milk in Sri Lanka. Canadian Agricultural Economics Society Annual Meeting. Montreal, Quebec.

5. Kilic, O., Akbay, C., \& Tiryaki, Y. G. (2009). Factors affecting packed and unpacked fluid milk consumption. Agric. Econ. - Czech, 557-563.

6. Mani, R., \& Intodia, V. (2014). India, Dairy and Products Annual 2014. Global Agricultural Informaiton Network.

7. Mousavi, S. A., \& Jahromi, M. M. (2014). EXAMINING THE RELATIONSHIP BETWEEN PACKAGING AND CONSUMER BUYING BEHAVIOR (CASE STUDY: COMPARISON OF PASTEURIZED 1.5L MILK OF BRANDS ROOZANEH AND MIHAN). Indian Journal of Fundamental and Applied Life Sciences, 10381044.

8. Sivasankaran, S., \& Sivanesan, R. (2013). Brand Preference of Packed Milk - Comparative Study on Rural and Urban Consumers In Kanyakumari District. International Journal of Business and Management Invention, 2335.

9. Sumathi, S. (2015). THE CUSTOMER PERCEPTION TOWARDS MARKETING OF DIFFERENT BRANDS OF PACKAGED MILK. International Journal of Research in IT \& Management, 36-43.

10. Yayar, R. (2012). Consumer characteristics influencing milk consumption preference. The Turkey Case. Theoretical and Applied Economics, 25-42. 